\title{
Introduction to the special issue on Tibet: Contemporary geodetic-geophysical observations and interpretations
}

\author{
Cheinway Hwang ${ }^{1, *}$, Wen-Bin Shen ${ }^{2}$, C. K. Shum ${ }^{3,4}$, and Xiaodong Song ${ }^{2,5}$ \\ ${ }^{1}$ Department of Civil Engineering, National Chiao Tung University, Hsinchu, Taiwan \\ ${ }^{2}$ School of Geodesy and Geomatics, Wuhan University, Wuhan, China \\ ${ }^{3}$ Division of Geodetic Science, School of Earth Sciences, The Ohio State University, Columbus, OH, USA \\ ${ }^{4}$ Institute of Geodesy \& Geophysics, Chinese Academy of Sciences, Wuhan, China \\ ${ }^{5}$ Department of Geology, University of Illinois at Urbana-Champaign, Champaign, IL, USA
}

Received 22 January 2019, Accepted 22 January 2019

Keywords: Altimeter, GNSS, GRACE, Lake level, Receiver function, SAR, Tibetan Plateau

Citation: Hwang, C., W.-B. Shen, C. K. Shum, and X. Song, 2019: Introduction to the special issue on Tibet: Contemporary geodetic-geophysical observations and interpretations. Terr. Atmos. Ocean. Sci., 30, 1-5, doi: 10.3319/TAO.2019.01.22.01

The Tibetan Plateau is known as the Third Pole of the Earth, playing unique roles in plate tectonics, glaciology, limnology, hydrology, climate, and environmental changes. Like major scientific hotspots elsewhere in the world, longterm geophysical data are needed for in-depth scientific studies. The Tibetan Plateau has very sparse and inadequate in situ data sets publicly available. However, large amount of satellite data have become available during the last few decades. Such data allow researchers to detect long-term evolutions of geophysical signals and to enable more accurate modeling of their mechanisms. These data, in combination with the limited available seismic/magnetic profiles and other in situ data, are poised to potentially be able to extract previously missing features vital to the interpretation of a targeted geophysical process.

To show the inadequate data density in Tibet, we use the example of GNSS station distribution. Figure 1 shows the distribution of GNSS stations in the mainland China (http://www.cgps.ac.cn/cgs/index.action). In the Tibetan region, only a few continuous GNSS stations exist. The point density of the campaign-mode GNSS stations is greater, especially in eastern Tibet, but there are no indications about the session lengths of the campaign-mode GNSS measurements, making it difficult to assess the accuracies of surface deformations determined from such measurements.

The most commonly used remote sensing data for geodetic studies in Tibet are from the GRACE twin-satellite gravity mission, synthetic aperture radar (SAR) and radar altimeter satellite missions. Figure 2 shows the rates of equivalent water height (EWH) from the NASA/Jet Propulsion Laboratory's (JPL's) GRACE Mascon (mass concen-

\footnotetext{
* Corresponding author

E-mail:cheinway@mail.nctu.edu.tw
}

tration) solution. An identified EWH decreasing trend near India and Pakistan (center at $30^{\circ} \mathrm{N}, 79^{\circ} \mathrm{E}$ ) is partially due to groundwater loss and glacier loss. The low around eastern Nepal and Bhutan (center at $27^{\circ} \mathrm{N}, 88^{\circ} \mathrm{E}$ ) is mainly due to glacier melts. The low in the eastern Himalayas (center at $30^{\circ} \mathrm{N}, 97^{\circ} \mathrm{E}$ ) is entirely due to glacier loss. The increasing trend in northern Tibet (center at $35^{\circ} \mathrm{N}, 90^{\circ} \mathrm{E}$ ) is associated with increased rainfalls that in turn raise lake levels during the GRACE data span. The positive EWH rates diminish from northern Tibet toward southern Tibet, implying less rainfall increases in Tibet's south. The increased EWH trend observed near the Karakoram Mountains (center at $36^{\circ} \mathrm{N}, 80^{\circ} \mathrm{E}$ ) is due to an anomalous glacier growth in the recent decade and a half with several hypothetical causes. The GRACE-derived EWH trends in Fig. 2 are consistent with the trends of lake level change given in Hwang et al. (2019). The climate data record generated by the GRACE mission is to be continued by the GRACE Follow-on mission (https:// gracefo.jpl.nasa.gov), with more than 2-year data gap.

Figure 3 shows the coverage of the SAR images over the Himalayas from Sentinel-1A, which is in a 12-day repeat observing cycle. The SAR-related works in this special issue are Du et al. (2019), Liu et al. (2019), and Tseng et al. (2019). With more publicly available SAR images from satellite missions like ESA's Sentinel-1A/-1B, and JAXA's ALOS and ALOS-2, publicly available SAR data processing software systems such as GMTSAR and others, SAR estimates of glacier melt rate, landslide and surface deformation in Tibet have been demonstrated. It is potentially feasible to cover the entire Tibetan Plateau for future studies using also InSAR (Interferometric SAR) and data from multiple SAR missions including Sentinel-1A/-1B, ALOS-2, TerraSAR$\mathrm{X}$, Tandem-X, and others. On the other hand, ground-based measurements such as those from GNSS and in situ glacier 
monitoring are needed for validations of satellite observations, as well as enable to measure the aforementioned geophysical or hazardous signals at a local scale.

Cryosat-2 is one of the most advanced radar altimeter systems in terms of data accuracy and spatial resolution, acquiring data in three modes (Low Resolution Mode or LRM, SAR mode, and SARIn mode using its two altimeters onboard). Figure 4 shows the global distributions of these observation modes of Cryosat-2. The SARin mode is the most accurate of all modes and covers over the entire Tibetan Plateau. Cryosat-2 altimeter data are used to detect changes in lake level, river water level and glacier height, which can be jointly used to determine the cause and effect of a particular climatic factor of interest. In particular, ablating mountain glaciers can reduce the water storage of the so-called Asia water tower in the high mountains of Asia that provides water for irrigation and drinking during the seasons without much rain. In this special issue, there is no paper on glacier changes using Cryosat-2 and other altimeters like ICESat around Tibet. Cryosat-2-based glacier studies in Tibet can be promoted to assess the GRACE-detected glacier changes in Fig. 2.

This special issue published 11 papers (out of 16 submitted papers) on contemporary geodetic-geophysical observations and their interpretations over Tibet. Some of the papers (earlier versions) were presented in the 8th TibXS meeting, 21 - 25 August 2017, at Mohe, Daxinganling District, China. Mohe is a county next to Siberia and is covered by permanent permafrost and dense forests. Like the previous TAO special issue on Tibet that was published in 2013 (Hwang et al. 2013), this current issue (2019) contains papers with rather diversified subjects. A summary of these papers and their interplays is given below.

\section{(1) Satellite-based global gravity model}

The model developed by Zhou et al. (2019) is important for determining large-scaled lithospheric elastic thickness (Eshagh et al. 2019) and long wavelength geopotential (geoidal) difference (Shen et al. 2019), among other geophysical and geodetic parameters.

\section{(2) GPS observation of earthquake potential}

Meng et al. (2019) used existing and new GNSS networks to detect surface deformations in the northeastern Tibet Plateau and determined the accumulated earthquake energy. This study is an example of using densified GNSS stations that deliver more details about the surface deformations of interest.

\section{(3) Lake level change, lake outburst and water storage change}

Hwang et al. (2019) used data from four altimeter satellites to show long-term lake level changes. At the interannual to decadal time scales, the altimeter-derived lake level changes are correlated with the gravity changes derived from
GRACE. Both the altimetry and gravimetry records indicate that water storages in Tibet have peaked in around 2014 2016 and started to decline after 2016. In addition, glacier melts caused by warming have increased runoffs to lakes around the Himalayas, raising the concerns of glacier lake outburst floods (GLOFs). Khadka et al. (2019) found that the areas of six lakes around the Himalayas have expanded, and these lakes could face the risks of GLOFs.

\section{(4) Glacier and landslide dynamics from SAR}

Du et al. (2019) used ALOS_PALSAR images to show the lowering of glacier elevation in southeastern Himalayas, where GRACE shows the largest loss of glacier mass (Fig. $2)$. SAR is not only used for detecting glacier change, but also for detecting landslide: Liu et al. (2019) used Sentinel1A SAR imagery (Fig. 3) to detect and predict landslides in Mao, a county at the borders of the Tibetan Plateau and Sichuan Province. As stated earlier, applications of SAR to detections of glacier change, landslide and surface deformation will be increasingly convenient and popular as more publicly available SAR images and processing tools are becoming available.

\section{(5) Precise atomic clock for geopotential determination}

Recent advancements in precise atomic clocks make it possible to determine the geopotential difference between two points, and subsequently the orthometric height of a new point (Shen et al. 2019). The greatest advantage of this method is that it requires no gravity measurements around the new point. However, the resulting orthometric height depends on the accuracy of the clock. More efforts for making precise clocks are needed to achieve orthometric heights at $\mathrm{cm}$ to $\mathrm{dm}$-level accuracies that have been achieved by GNSS leveling.

\section{(6) Flood detection using satellite imageries}

Tseng et al. (2019) built a satellite-based, efficient surface water monitoring system in Syhlhet, an important economic zone of Bangladesh that has long suffered from groundwater loss and land subsidence. A potential link to the study of Tseng et al. (2019) with that of Hwang et al. (2019) is the effect of the declining water storage around the Yarlung Tsangpo River, which is the upstream of the Brahmaputra River that flows by Syhlhet and into the Bay of Bengal. Since the flows of the Yarlung Tsangpo River are mostly contributed by the meltwater from glaciers in southern Tibet and northern Himalayas, less meltwater in these two source regions usually means less flows of the Brahmaputra River (Hwang et al. 2019).

\section{(7) Moho and lithosphere theory and model}

Eshagh et al. (2019) used two methods to estimate the lithospheric thickness in central Eurasia. Their model result suggests the largest Moho depths over the Tibetan Plateau, consistent with previous studies based on different approaches, 


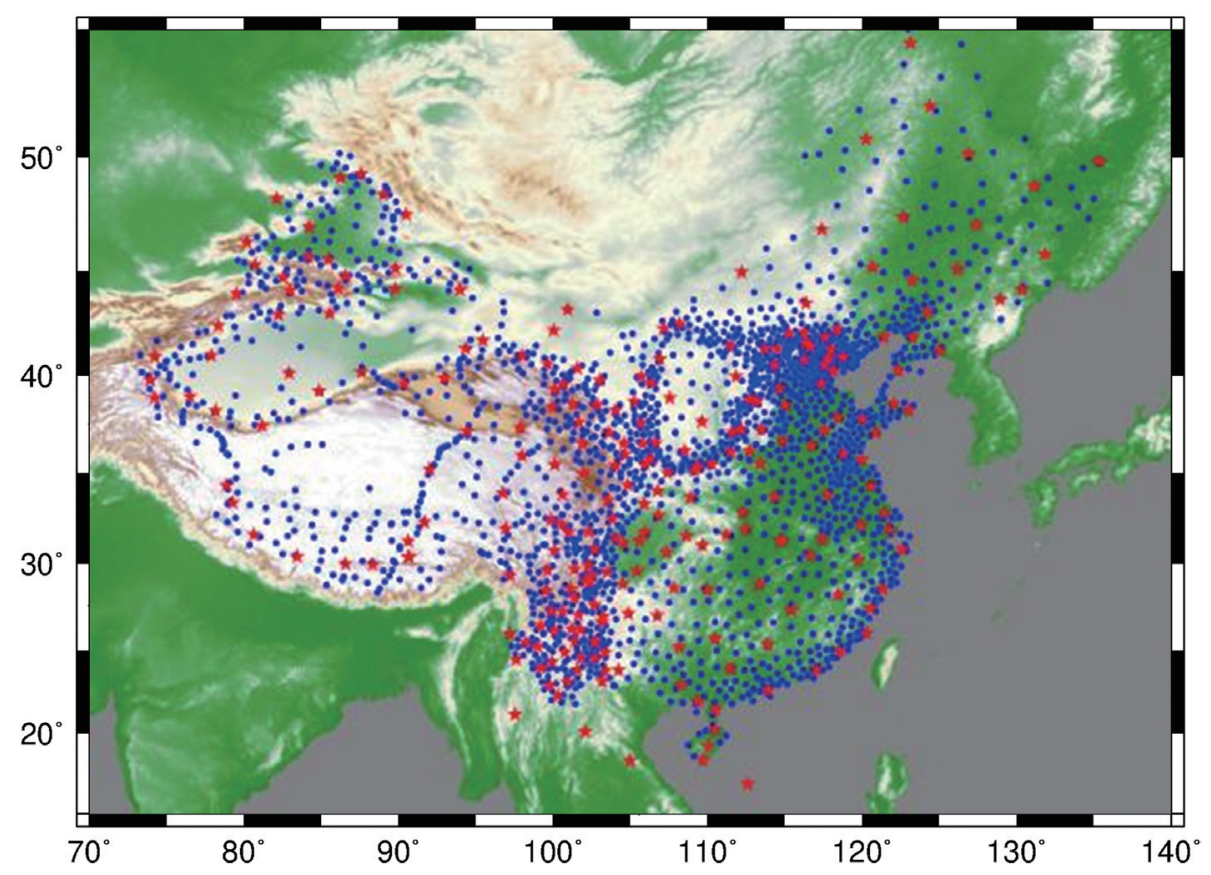

Fig. 1. Distributions of the 260 continuous GNSS stations (red stars) and the 2000 campaign-mode (regional) GNSS stations (blue solid dots) based on the information given by the China Earthquake Administration. This figure is modified and enriched from a figure at http://www.cgps.ac.cn/. The availability of GNSS measurements are critical in the geophysical interpretations of geodynamics and earthquakes, such as Deng et al. (2019), Meng et al. (2019), Shen et al. (2019), and Sun et al. (2019).

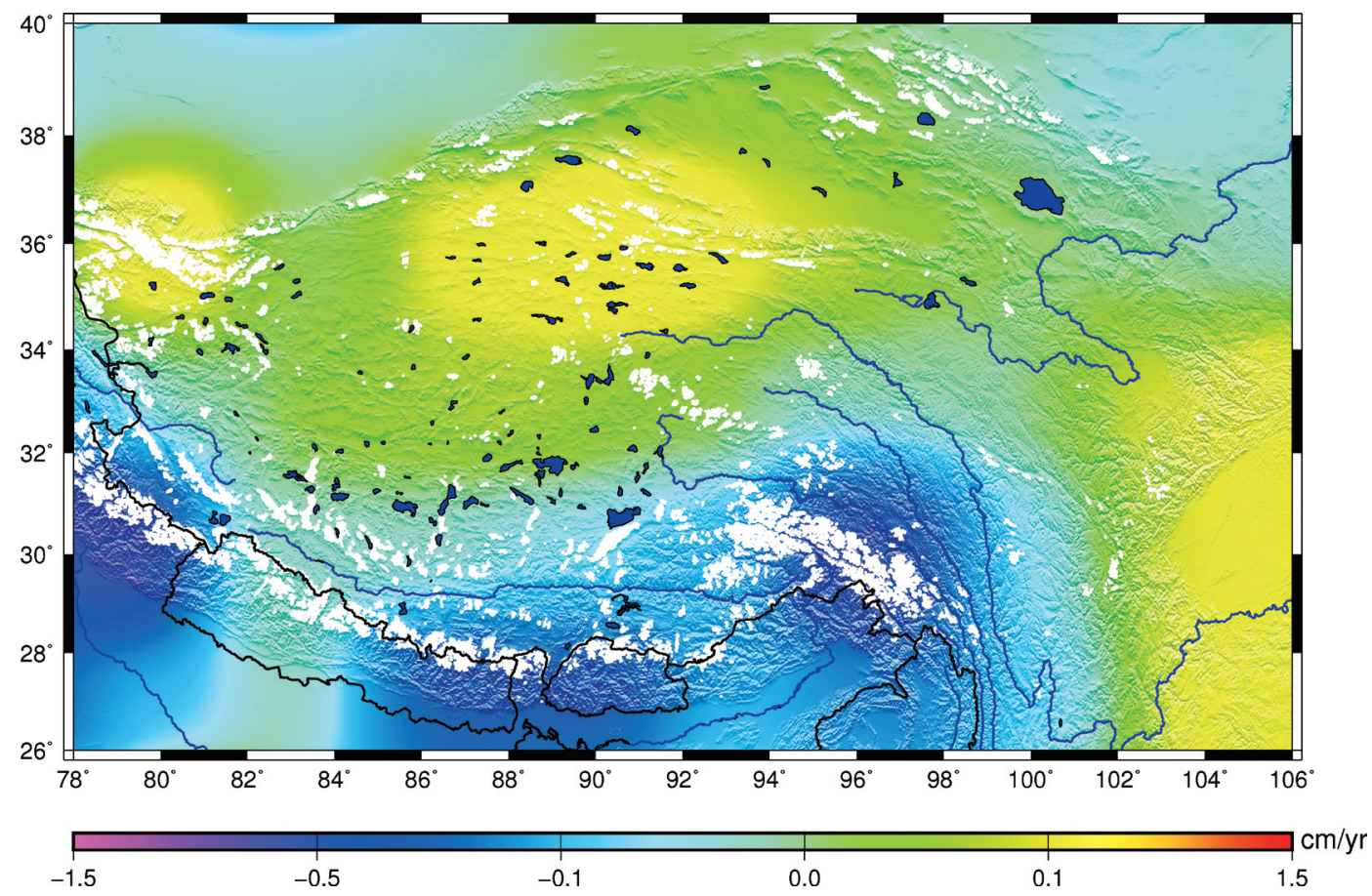

Fig. 2. GRACE-derived rates of equivalent water height (EWH) around Tibet over 2003 - 2015 from the JPL RL05M.1 Mascon Solution. The names of the major rivers and lakes (deep blue-shaded) in this figure are given in Hwang et al. (2019). The locations of glaciers (white-shaded) are from the World Glacier Inventory (WGI) at https://nsidc.org/data/glacier inventory. 


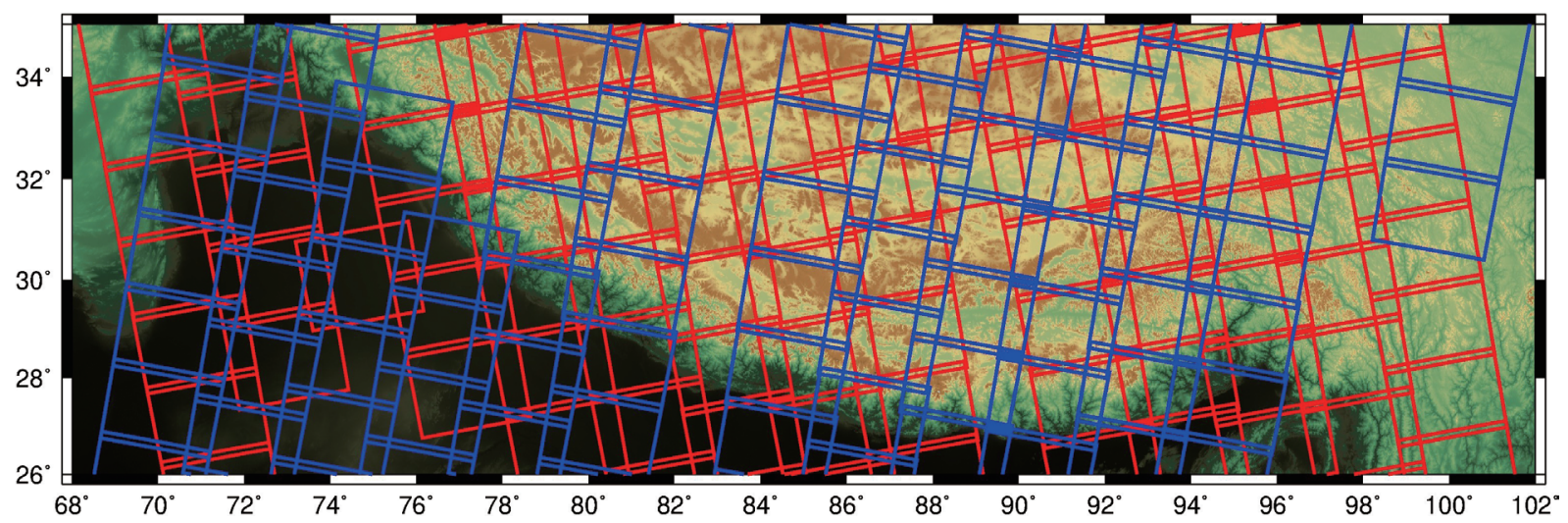

Fig. 3. The coverages of Sentinel-1A SAR images in a 12-day repeat cycle over the Himalayas. A rectangle represents a SAR frame along an ascending (red) and descending pass (blue). With such coverages, glacier changes in the entire Himalayas can be mapped every 12 days using Sentinel-1A images without the concern of cloud obstructions.

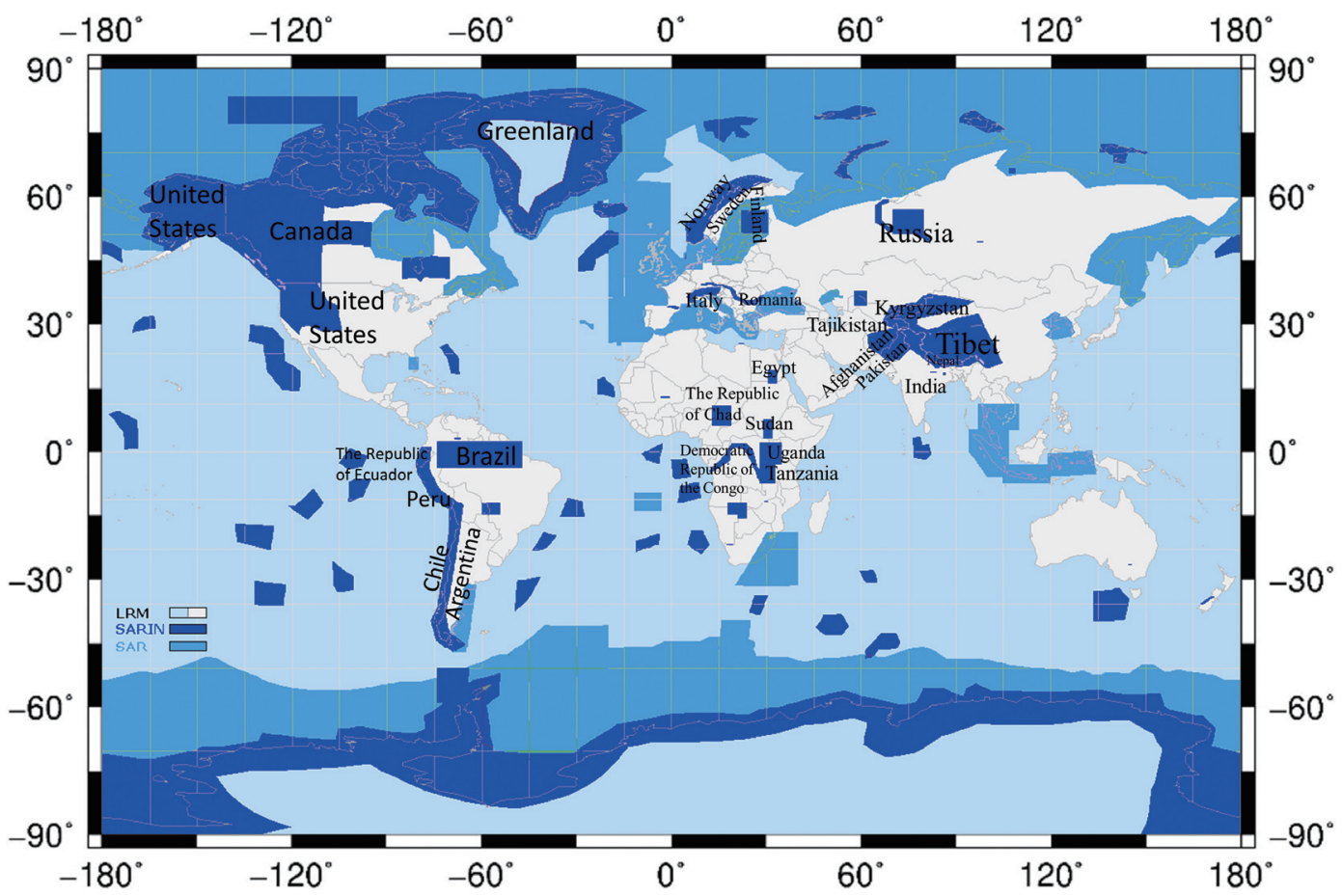

Fig. 4. The spatial coverages of the SARin observation mode of Cryosat-2 (blue shaded) over Tibet and other parts of the world. The image is modified from a figure at https://earth.esa.int/documents.

and with the results of Deng et al. (2019) and Sun et al. (2019) in this special issue. Deng et al. (2019) imaged lithosphere structure using receiver function and surface wave dispersion. The result of Deng et al. (2019) suggests a coupled lithospheric-scale deformation of a local lithosphere or a non-uniform southward subduction of Asian lithosphere.

\section{(8) Results of the superconducting gravimeter observa- tions at Lhasa}

Sun et al. (2019) show that the amplitude factors around the Tibetan Plateau estimated from superconducting gravimeter
(SG) records are $0.34 \%$ larger than that in Wuhan, which is located over a low-altitude plain. The differences in the amplitude factors are partially attributed to the high altitude of the SG stations and the large elastic thickness of the Tibetan Plateau. The result from Sun et al. (2019) can potentially be linked to the results of Deng et al. (2019) and Eshagh et al. (2019).

Acknowledgements We thank the responsible editor, Prof. Shu-Kun Hsu, and the editorial assistant, Ms. Pei-Cin Jheng for their supports in handling and copy/editing the papers. 
We thank all reviewers for their valuable comments that improved the quality of the papers.

\section{REFERENCES}

Deng, Y., J. Li, X. Song, H. Li, and T. Xu, 2019: The lithospheric-scale deformation in NE Tibet from joint inversion of receiver function and surface wave dispersion. Terr. Atmos. Ocean. Sci., 30, 127-137, doi: 10.3319/ TAO.2019.01.18.03. [Link]

Du, W., X. Liu, J. Guo, Y. Shen, W. Li, and X. Chang, 2019: Analysis of the melting glaciers in Southeast Tibet by ALOS-PALSAR data. Terr. Atmos. Ocean. Sci., 30, 7-19, doi: 10.3319/TAO.2018.07.09.03. [Link]

Eshagh, M., M. Pitoňák, and R. Tenzer, 2019: Lithospheric elastic thickness estimates in central Eurasia. Terr. Atmos. Ocean. Sci., 30, 73-84, doi: 10.3319/ TAO.2018.09.28.02. [Link]

Hwang, C., K. Heki, W. Shen, and C. K. Shum, 2013: Preface to the special issue on "geophysical and climate change studies in Tibet, Xinjiang, and Siberia (TibXS) from satellite geodesy." Terr. Atmos. Ocean. Sci., 24, I, doi: 10.3319/TAO.2013.04.17.01(TibXS). [Link]

Hwang, C., Y.-S. Cheng, W.-H. Yang, G. Zhang, Y.-R. Huang, W .-B.Shen, and Y.Pan, 2019: Lake level changes in the Tibetan Plateau from Cryosat-2, SARAL, ICESat, and Jason-2 altimeters. Terr. Atmos. Ocean. Sci., 30, 33-50, doi: 10.3319/TAO.2018.07.09.01. [Link]

Khadka, N., G. Zhang, and W. Chen, 2019: The state of six dangerous glacial lakes in the Nepalese Himalaya. Terr. Atmos. Ocean. Sci., 30, 63-72, doi: 10.3319/ TAO.2018.09.28.03. [Link]
Liu, Y., C. Xu, and Y. Liu, 2019: Monitoring and forecasting analysis of a landslide in Xinmo, Mao County, using Sentinel-1 data. Terr. Atmos. Ocean. Sci., 30, 8596, doi: 10.3319/TAO.2018.10.16.01. [Link]

Meng, G., X. Su, W. Xu, C.-H. Chen, K.-C. Cheng, S. Wen, T.-K. Yeh, P. Li, M. Ohzono, and H. Takahashi, 2019: Present-day strain accumulation in the Liupan Shan area, northeastern margin of the Tibetan Plateau by GPS observations. Terr. Atmos. Ocean. Sci., 30, 51-62, doi: 10.3319/TAO.2018.09.10.02. [Link]

Shen, W.-B., X. Sun, C. Cai, K. Wu, and Z. Shen, 2019: Geopotential determination based on a direct clock comparison using two-way satellite time and frequency transfer. Terr. Atmos. Ocean. Sci., 30, 21-31, doi: 10.3319/TAO.2018.07.09.02. [Link]

Sun, H., H. Zhang, J. Xu, X. Chen, J. Zhou, and M. Zhang, 2019: Influences of the Tibetan Plateau on tidal gravity detected using superconducting gravimeters in the Lhasa, Lijiang, and Wuhan Stations in China. Terr. Atmos. Ocean. Sci., 30, 139-149, doi: 10.3319/ TAO.2019.02.14.01. [Link]

Tseng, K.-H., C.-Y. Kuo, M.-H. Lo, C. K. Shum, M. M. Rahman, Y. Jia, T.-Y. Yang, and P.-H. Shih, 2019: Using MODIS/Terra and Landsat imageries to improve surface water quantification in Sylhet, Bangladesh. Terr. Atmos. Ocean. Sci., 30, 111-126, doi: 10.3319/ TAO.2018.11.15.04. [Link]

Zhou, H., C. Xu, Z. Luo, Z. Zhou, B. Zhong, and J. Wan, 2019: HUST-GOGRA2018s: A new gravity field model derived from the combination of GRACE and GOCE data. Terr. Atmos. Ocean. Sci., 30, 97-109, doi: 10.3319/TAO.2018.11.02.01. [Link] 